\title{
Regulating and Taxing the Big Tech Companies: A Slippery Slope for Africa?
}

\author{
Dr. Mohammed Suleh-Yusuf ${ }^{1}$ \\ Researcher on Cyber Security, Data Privacy \& AML/CFT Regulations
}

\begin{abstract}
There has been a growing concern across the globe on the activities of Big Tech companies and the platforms they deploy. This Paper reviews the United States and European experiences, while also providing an African perspective. It is unclear how Africa should proceed with its regulatory oversight of the Big Tech companies and subsequently tax them appropriately. Doubtlessly, the African continent lacks the policy cohesion of Europe, the cross national enforcement capabilities of the United States or even the capacity to monitor that actual activities on these platforms. Therefore, this Paper is of the view that Africa must segment the activities of the Big Tech companies based on both the thematic functions of their platforms and the regulatory areas they impact in the countries they operate in. In the end the key question, which is also an expression of a deep seated fear, is on whether this path can be a slippery slope that will capsize even the fringe advantages and usefulness of these platforms on the African digital ecosystem.
\end{abstract}

Keywords: Big Tech, Regulatory, Platforms, taxation, technologies, communications

DOI: $10.7176 / \mathrm{EJBM} / 13-20-12$

Publication date:October $31^{\text {st }} 2021$

\section{Introduction}

The exponential growth in technology and communications is evidenced by the astronomical number of connected devices globally, which is projected to increase from 30.4 billion in 2020 to 200 billion in $2030^{2}$. This unprecedented connectivity of objects, places and people will result in new products, smarter services and, niche business models. This exponential growth is better viewed from the type of business models of many large technology companies, which is built to maximize the frequency and duration of use of their platforms, generate zillions of data and 'stereotype' them for business planning, marketing and consumer behavioural analysis. A recent statistics shows that the average American spends just over $40 \%$ of their waking hours online, with that number approaching $60 \%$ for American teens ${ }^{3}$. A growing body of research problematizes the "choice" to spend this much time online. Today's dominant digital platforms are intentionally designed to produce structural and functional changes in various regions of the brain and to trigger the same brain reward pathways as nicotine and other addictive drugs. Thus far, such platforms have managed to almost entirely avoid liability for harms associated with their use.

In Africa and most of the third world, digital technologies harnessed through smartphones have been deployed widely to support access to digital platforms and related services. This phenomenal connectivity has also posed several challenges for the governments in the continent and opened up conversations on fiscal and regulatory responsibilities of the Big Tech companies driving these services. These challenges also revolve around the traditional conflict themes such as respect for human rights, free accessibility to information and unhindered right to associate, albeit via online and virtual; platforms. Though it is fair to admit that these challenges are not restricted to the African continent, other climes have also faced different strata of difficulties/challenges in managing the activities of the Big Tech vis- àvis the rights of their citizenry.

There has been a strident and mounting call to regulate the world's largest technology companies and the word "techlash"4 (referring to the threat of a consumer and/or regulatory revolt against Big Tech companies) has entered the modern lexicon. Beyond the hues and cries there is a consensus that the current business model and commercial behaviour of the world's leading technology companies has to change or at least reform. But what exactly needs to change or reform? First, there is a growing worry that the Big Tech engage in abysmal privacy practices and the misuse of personal data. Secondly, several Regulators, particularly in Europe, express concerns about the monopoly power of the Big Tech. While in some climes there is a third concern that relates to a perception that Big Tech are suppressing lawful speech, while others warn that Big Tech's failure to curb the spread of misinformation and hate on digital platforms has threatened the very foundations of democracy. Certainly most of these concerns are justifiable and in most cases quire factual, yet none has actually captured the underlying problem: how do we bring the Big Tech to a regulatory table and ensure they pay their fair share of taxes to the developing

\footnotetext{
${ }^{1}$ LL. B (Hons) Maiduguri, BL (Lagos), LL.M (Aberdeen), PhD (NSU)

${ }^{2}$ Jacobides, M. G. (2020). Regulating Big Tech in Europe: Why, so what, and how understanding their business models and ecosystems can make a difference. Available at SSRN 3765324

${ }^{3}$ ibid

${ }^{4}$ Reding, V. (2015). Digital Sovereignty: Europe at a Crossroads.
} 
world.

Thus it is necessary to understand the Big Tech before regulating them and we may review some of the characteristics of the Big Tech that complicates any regulatory approach. First, the Big Tech platforms has complex antitrust, privacy and speech rules that ensure consumers have 'willingly' given up their rights. Secondly, it is always difficult to analyse why Big Tech companies have no serious competitors, the fact that they have relied entirely on the psychological vulnerabilities of hordes of people to make billions of users' dependent on their platforms is indicative of the reason why they thrive with no competition. Thirdly, it is clear that users and consumers of the services being offered by the Big Tech may have consciously jettison users' consent to sacrifice privacy in exchange for the privilege of access to the addictive platforms. Lastly, the reason that Big Tech's approach to free expression has become such a pivotal issue globally is mostly likely because so much of modern speech and social engagements are happening on these digital platforms, particularly Facebook, Twitter and Instagram. This is may be a consequence of the Big Tech's core business model that is strategically designed to be as addictive as possible.

This Paper focuses on Big Tech companies that deploy platforms that generate revenue by maximizing user attention at the greatest frequency and for the longest duration possible and operate across different jurisdictions through the internet. This includes various social media sites such as Facebook, Instagram, LinkedIn, and Snapchat Based on their business models these platforms depend on revenue from advertisers and direct purchases by its users. This focus examines the impact of the Big Tech companies and considers whether existing regulations offer sufficient oversight powers to African countries to regulate them and seek taxes for the services deployed in their territory. Although there are millions of users of these platforms in Africa, there is no evidence that any of the known Big Tech companies is under the regulatory oversight of any African country or whether they even pay requisite taxes to these countries.

The popular digital platforms such as Facebook, Netflix, Google, Snapchat, Twitter and YouTube, are incorporated in the United States. This creates an undue advantage for them and also cloak them in the majestic garment of American power. Consequently, the US-incorporated Big Tech companies have expanded across the globe and seem to have the expansionary attitude of American international ambitions, with its attendant contradictions and challenges. This expansion has also been impacted by the different global elbowing between US and China, US and Europe and Russia with everyone else. Yet the developing countries have been unable (or neglected) to either regulate these platforms or at a minimum collect taxes for their operations in their territories. Although these platforms are neither incorporated nor physically in most developing countries, it is clear that they have users ${ }^{1}$, consumers and revenue-generating activities in these areas.

There is no data that indicates the explosive growth of the business or tremendous powers of the Big Tech companies than the fact that they now occupy all the top-five spots in terms of market capitalization worldwide. In fact, Big Tech companies such as Google, Apple and Facebook ('GAF') have built business models that brought users great convenience in the form of an ever-increasing array of services, some offered directly and most of them by a set of co-specialized ecosystem participants that rely on their platforms. However, they have also as a result become significantly more powerful and posed significant challenges to governments and regulators across the globe. Thus, there has been a heated ongoing debate on whether the frameworks, laws and regulations currently in place in most countries and regions in the world are sufficient to address the challenges posed by these entities. It is becoming clear that an in-depth assessment may be necessary to determine this adequacy issue and also the capacity of governments and regulators to superintend over these 'super' Big Tech companies. While the Big Tech companies themselves, and a few pundits and researchers, continually assert that their explosive successes are the natural consequence of their amazing commercial prowess, there is growing unease globally about their increasing dominance and potential abuse of their position. The key concern lies in the capacity of governments and regulators to understand the business modelling of the Big Tech companies and their activities restrict competition and potentially limit innovation in their areas of operation. More so there is a growing concern that their aggressive business modelling is also detrimental to both its users/consumers and other players in the ecosystems they control.

In 2019, three impactful reports reviewed why digital competition is different from traditional competition: the Stigler Report in the US ${ }^{2}$, the Furman Report by the UK Treasury (HMRC) ${ }^{3}$ and the Data Report from the EU ${ }^{4}$. All three reports identified significant shortcomings in analysis, monitoring and regulatory enforcement, and pointed to the need for a new, or at least stronger approach. We have to admit that the Big Tech's meteoric growth, lateral expansion and acquisitive appetite have only complicated matters for countries that lack the stature and capacity to push back their expansionary tendencies. The reports may have outlined a global challenge but it lacks the ingredients that will dovetail into the teething and mundane challenges being faced by developing countries.

\footnotetext{
${ }^{1}$ Akman, P. (2021). A Web of Paradoxes: Empirical Evidence on Online Platform Users and Implications for Competition and Regulation in Digital Markets. Available at SSRN 3835280.

${ }^{2}$ First, H., \& Fox, E. M. (2020). Big Tech and Antitrust-Calling Big Tech to Account Under US Law. Available at SSRN 3672750.

${ }^{3}$ Ibid

${ }^{4}$ Ibid
} 
These teething challenges revolve around basic regulatory capacities, enforcement capabilities and adequate legal frameworks for managing the activities of these 'massive' Big Tech companies.

Then there is the issue of the Big Tech companies meddling in the affairs of countries and even the broader suspicion that they have corrosive effect on democratic processes, particularly in countries with weak institutions. The big question is whether the ability of the Big Tech companies to cultivate dependency and increase consumption of their services is at the expense of consumer welfare. Perhaps the most evident issue is whether these cultivated dependency and unregulated consumption by citizens of a country with weak democratic institutions can be exploited to incite insurrection or even instigate anti-government protests. The current altercations $^{1}$ between Twitter and the Nigerian government readily comes to mind as well as the \#endSARS protests $^{2}$ that may have founded the current conflict. What this shows is that the quest to regulate the Big Tech by the countries in Africa may be related to matters outside the realm of competition, data protection and taxation. The quest may also be driven by the perceived impact of these Big Tech companies on the democratic process, ironically this may also be the soft belly of this postulation as the continent has a dicey relationship with democratic ethos and rights of its citizenry.

\section{The Big Tech Companies}

In the last 20 years, new technologies have evolved and from that evolution sprout out Big Techs companies especially Google, Apple, Facebook, Amazon and Microsoft (GAFAM) in the United States and Baidu, Alibaba and Tencent (BATs) in China. These Big Tech companies permeate all aspects of life and dominate economies across regions globally. The Big Tech companies have developed from the combination of technological evolution such as digitization, datafication, and digitalization. They have also benefitted immensely from the conducive regulatory approaches in the US and China in particular (at least prior to 2019-2020). ${ }^{3}$ Noteworthy is the fact that the resulting concentration and dominance have long been a source of concern in the European Union, while the recent concentration and dominance in the US and China have emerged as major social, political, regulatory and legal worries tied to the need to balance the emergent benefits of o platforms of the Big Tech companies for consumers against concerns about abuses of data and market position. Consequently, the internal governance of Big Tech companies and their business modelling are emerging as major issues for the twenty-first century and lie at the heart of balancing the benefits and risks of the "digitization of everything" in the Fourth Industrial Revolution.

Digital platforms such as Facebook create value by connecting users, vendors, and contractors in a seamless manner that defies physical restrictions of commerce. These immense capacity for connectivity has also created a strong supply and demand economies of scale that give the Big Tech companies' naked market power that dwarfs the abilities of national regulators. This has led to increasing campaign to tweak regulations and ensure proper taxes are paid. The business model of the Big Tech companies allows for demand elasticity ${ }^{4}$, disutility from advertising ${ }^{5}$ and network effects across users. Facebook creates $\$ 14$ billion ${ }^{6}$ in social value per month, with consumer surplus concentrated among female and older users of Facebook. This further illustrates the immense financial powers of the Big Tech companies and this has a way of narrowing their exposures. Yet the full economic impact of these firms can be better appreciated by reviewing some macro - statistics. First, the five largest Big Tech companies combined had just over $\$ 800$ billion of revenues in $2018^{7}$ and if they were countries, they would be among the world's 20 largest in terms of Gross Domestic Product (GDP). Secondly, by early 2020 each of the five had a market capitalisation of $\$ 1$ trillion or more, making up $17 \%$ of the S\&P 500 total market value. Meanwhile in 2006, the five largest firms in the U.S. were Exxon Mobil, General Electric, Microsoft, Citigroup, and Bank of America ${ }^{8}$. But by 2017 GAFA had replaced four of the five, with only Microsoft surviving the Big Tech onslaught.

\footnotetext{
${ }^{1}$ The Nigerian Government suspended Twitter operations in Nigeria on June 5, 2021

${ }^{2}$ It is the hashtag on social media for a protest against police brutality that turned violent and heavily politicised

${ }^{3}$ Kwet, M. (2019). Digital colonialism: US Empire and the new imperialism in the Global South. Race \& Class, 60(4), 3-26.

${ }^{4}$ Marco Colino, S. (2021). Towards a Global Big Tech Clampdown?. Agenda Pública, The Chinese University of Hong Kong Faculty of Law Research Paper, (2021-04)

${ }^{5}$ Ibid

${ }^{6}$ Ibid

${ }^{7}$ Ibid

${ }^{8}$ Ibid
} 


\begin{tabular}{|l|l|l|}
\hline Big Tech & May 2014 & May 2019 \\
\hline Apple & \$510.44B & $\$ 962.31 \mathrm{~B}$ \\
\hline Google & \$355.60B & $\$ 807.13 \mathrm{~B}$ \\
\hline Microsoft & $\$ 327.86 \mathrm{~B}$ & $\$ 967.12 \mathrm{~B}$ \\
\hline Facebook & $\$ 155.16 \mathrm{~B}$ & $\$ 549.57 \mathrm{~B}$ \\
\hline Amazon & $\$ 141.74 \mathrm{~B}$ & $\$ 935.83 \mathrm{~B}$ \\
\hline
\end{tabular}

Table 1: Market Capitalisation of the Big Tech companies ${ }^{1}$

We must acknowledge that the Big Tech companies have advantages that can also impact on any quest to rein them in and regulate them as appropriate. First, the Big Techs companies enjoy increasing numbers of users on their platforms as more people around the world gain access to smartphones and internet browsing capabilities. These growing connectivity is primarily aided by user-friendly application programming interfaces (APIs) that enables them to offer a series of services through a platform-based model that connects users across a vast global network. The connections vary depending on the type of website, as they can be on social media sites or comprise buyers and sellers across a range of industries and enterprises. Secondly, the Big Tech companies rely on the application of relatively new technology and tools which have of late matured significantly. These technologies consist primarily of artificial intelligence, big data, cloud computing and they offer the Big Tech companies windows into lives of their users and commercialisation of their personal data.

The sheer size and global spread of the Big Tech companies poses systemic and cross-border risks that can be perplexing and daunting for regulators and policymakers. A good illustration of these challenges is that national regulators now have to grapple with the Big Tech companies accumulating vast amounts of data in ways that raise barriers to entry, support anticompetitive practices, and present novel risks to consumers' data privacy and protection. A second illustration is the fact that this evolutionary growth of the Big Tech companies results in a cycle of concentration and dominance. Thus, data and technology businesses are often characterized as 'winnertakes-all' or 'winner-takes-most' industries, in which oligopolies or even monopolies are a natural result. This creates competition issues and may affect the market balance in areas where these Big Tech companies are not even registered to operate.

\section{The USA Experience}

The American Big Tech companies have metamorphosed into goliaths dominating the global economy and serving as the fulcrum of global digital commerce. Farhad Manjoo ${ }^{2}$ referred to them as "the Frightful Five": Amazon, Apple, Facebook, Microsoft, and Google and if listed in the order of their market capitalisation they will be Apple, Microsoft, Google, and Amazon. These Big Tech are dominating digital technology and having primacy in selected areas. A good illustration of this domination by the American Big Tech can be discerned from the overwhelming domination of the search engine segment by Google and its primacy in web browsing through Google chrome; the seeming domination of smartphones operating systems by Google Android and Apple iOS. We also have the market covering domination of desktop and laptop operating systems by Microsoft Windows, software by Microsoft Office and Google Docs. While Amazon, IBM, Microsoft and Google are firmly driving cloud infrastructure and services across the digital globe. Yet it is in the social media spectrum that the American domination is so pervasive, Facebook, Twitter, LinkedIn, YouTube and Instagram represent this domination. These five leading Big Tech companies, Google, Apple, Facebook, Amazon and Microsoft, are not just dominating, they are also the five wealthiest companies in the world, with a combined market capitalisation exceeding $\$ 3$ trillion ${ }^{3}$.

Although the American Big Tech companies are rooted in the country, they have not escaped scrutiny within the United States. The same concerns being raised in Europe and other regions have also been voiced within the United States. In fact in 2019 the U.S. Department of Justice and the Federal Trade Commission announced investigations into GAFA ${ }^{4}$; this was a necessary response to the rising concerns on their activities. They have also faced legislative oversight and on July 29, 2020, the Antitrust Subcommittee of the U.S. House Judiciary Committee called the CEOs of Google, Apple, Facebook, and Amazon to testify for more than five hours ${ }^{5}$. They have also faced litigations from the governments in the United States and as a result on October 20, 2020, the U.S. Department of Justice and eleven state Attorneys General filed a monopolization suit against Google ${ }^{6}$, the first such suit since the monopolization case against Microsoft more than two decades before ${ }^{7}$. The U.S. suit against

\footnotetext{
${ }^{1}$ https://www.statista.com/chart/17875/market-capitalization-of-selected-tech-companies/

${ }^{2}$ First, H. (2021). Digital Platforms and Competition Policy in Developing Countries. Harry First, Digital platforms and competition policy in developing countries, mai.

${ }^{3}$ Ibid

${ }^{4}$ https://www.wsj.com/articles/ftc-plans-to-examine-past-acquisitions-by-big-tech-companies-11581440270

${ }^{5}$ Ibid

${ }^{6} \mathrm{https}$ ://www.voanews.com/a/silicon-valley-technology_us-justice-department-11-states-sue-google/6197366.html

${ }^{7}$ Ibid
} 
Google was then followed by two more suits against Google filed by two different groups of states ${ }^{1}$. Facebook was then sued by the FTC and by another large group of states ${ }^{2}$. Clearly the United States has not been a haven for the Big Tech companies.

It is worth noting that these rising concerns on the activities off the Big Tech companies are not limited to the United States, of course. The European Union have been voicing these concerns and have even taken certain enforcement actions and also made policy decisions to limit and manage the activities of the Big Tech companies. As in the United States, the European Commission has brought three separate cases against Google for abuse of dominance $^{3}$, imposing fines of more than $\$ 5$ billion $^{4}$. There have also been individual national actions within Europe to curtail the activities of the Big Tech companies. This has culminated in; first, Germany suing Facebook, linking competition law with privacy protections; secondly the United Kingdom's Competition and Markets Authority has published a final report of its market study on online platforms and digital advertising. These situations have shown that the main concerns of the United States and Europe revolves around the impact of the activities of the Big Tech companies on the citizens, consumers, and economies of the United States and Europe.

The American examples above and the European reactions are pointers to the immense powers being wielded by the Big Tech companies through the platforms they created. These immense powers need to be tempered with regulatory oversight, not just in the United States and Europe but also across the globe where these Big Tech companies operate. Though we must admit that the activities of these Big Tech companies also present benefits for developing countries that can be harvested for economic benefits. It also presents an avenue for fiscal revenue through proper and adequate taxation of the activities of the Big Tech companies because the platforms have become basic tools for digital platform commerce and development. They open the possibility of providing a market presence and access for small and medium businesses that might otherwise find it difficult to reach consumers in domestic and international markets. This is an important ground for developing countries to harness rather than curtail the activities of the Big Tech companies.

\section{The European Experience}

In recent times ${ }^{5}$ there has a growing appetite in Europe to regulate the Big Tech companies and there is an unsaid quest to empower the European tech ecosystem, reshape the regulations in the digital space and face the 'foreign' Big Tech companies squarely. We have already acknowledged that the rising power of the Big Tech companies worries even the United States, but it has reached a frenzy level in Europe. The European continent has been on an overdrive of recent to actively and properly regulate the Big Tech companies. More so this European frenzy is an admission of the actual impact of Big Tech companies and their disruptive effect on the tech ecosystem in Europe. This admission also gives life to the contention that the rise of large digital platforms and their ecosystems raises new regulatory challenges, as existing tools are unfit to grapple with true power in the digital economy. On the other hand, it also is clear that geopolitics is driving much of the debate, with the EU reacting with profound skepticism to firms based in the US, which also engage in unfair practices ${ }^{6}$.

In recent years, Europe has also been concerned with competition issues, matters of user choice, privacy of data and social disruptions arising from the platforms of the Big Tech companies. The continent is also innately worried about lagging behind technologically and face the inevitable risks that accompanies the Big Tech companies; powers over consumers, data and commercial partners. This European concern may have propelled the continent into leading the way in building new regulation and also active policing of the activities of the Big Tech companies operating in Europe. Unfortunately, there is also a belief in some quarters that the European drive to regulate and tax the Big Tech companies is being motivated by geopolitics considerations rather than technology or commerce. The European's regulatory overdrive seem focused on matters related to Market Definition, ePrivacy, competition (i.e., fairness) and taxation. In terms of competition, the European concern is that Big Tech firms exploit their customers or the complementors (such as app developers) who support their ecosystems. Secondly, Europe is also has a strategic problem with the fact that most of the Big Tech companies providing the digital platform, that dominate the consumer market, are US-based or Chinese ${ }^{7}$.

In a book ${ }^{8}$ published in 2020 Anu Bradford described how the European Union remains an "influential superpower that shapes the world in its image", including the digital sphere. The term "Brussels Effect" refers precisely to the European Union's unilateral power to regulate global markets. Bradford observes that "the EU has become the global regulatory hegemon unmatched by its geopolitical rivals. [This] challenges the critics' view

\footnotetext{
${ }^{1}$ https://www.theguardian.com/technology/2020/dec/17/google-antitrust-lawsuit-states-search

${ }^{2} \mathrm{Ibid}$

${ }^{3}$ https://www.cnbc.com/2020/12/18/google-antitrust-cases-in-us-and-europe-overview.html

${ }^{4}$ Ibid

${ }^{5}$ There have several cases against the Big Tech companies in Europe in the last three years with heavy fines imposed on some of them

${ }^{6} \mathrm{https}: / /$ www.washingtonpost.com/technology/2020/11/10/eu-antitrust-probe-google/

${ }^{7}$ Ibid

${ }^{8}$ Bradford, A. (2020). The Brussels effect: How the European Union rules the world. Oxford University Press, USA.

${ }^{9}$ Ibid
} 
that portrays the EU as a powerless global actor, and shows how such a criticism focuses on a narrow and outdated vision of what power means today" ". Bradford highlights that the EU today: "promulgates regulations that influence which products are built and how business is conducted, not just in Europe but everywhere in the world" 2 . In her view the most remarkable part of that conclusion is the fact that Europe is able to achieve this primacy without relying on any power, or dishing out by sanctions or other means of coercion. Rather it the Market forces that enabled the continent to convert its own standard into the global standard ${ }^{3}$.

Bradford postulates that Europe's regulatory primacy is hinged on three factors. First, the European market is so enormous - roughly a fifth of global GDP at market exchange rates - that producers cannot ignore the continent, no matter how onerous its regulation ${ }^{4}$. Second, in contrast to the US where light-touch regulation is often the goal, Europe revels in making its rules exacting and prides itself on having the toughest regulations on everything from privacy to the environment ${ }^{5}$. These two factors combine to introduce a third factor of influencing global regulation, as different stakeholders (NGOs, local governments, politicians and the companies themselves) lobby their domestic governments to raise their regulations to European levels ${ }^{6}$. The Brussels Effect thus leads, under some conditions, to "unilateral regulatory globalization" " where "regulations originating from a single jurisdiction penetrate many aspects of economic life across the global marketplace" 8 . This situation does not occur without reaction. As Bradford points out, some commentators go as far as to allege that the externalization of the EU's single market reflects "imperialistic" motives. According to these critics, "the EU is seeking to exert political and economic domination over other countries". But the EU "counters these criticisms by arguing that it is not engaged in coercion - it is not using force or threats to persuade any company or government to do anything - in particular, when the EU is exporting its rules through the market-driven Brussels Effect. Instead, the EU is simply asking others to play by its rules when operating in its home market, and enforcing the norms of the single market equally on domestic and foreign players" 10 . In addition, the EU "often defends its regulatory reach by portraying itself as a benign global hegemon, whose values and policies are both normatively desirable". ${ }^{11}$

From privacy to data protection, from competition issues to protecting copyright and publisher's rights, from fighting hate speech and disinformation online to taking the lead on Artificial Intelligence regulation, the EU has been a spectacular leader in digital regulation ${ }^{12}$. If "digital sovereignty" means regulatory power, there is indeed little doubt that Europe is "sovereign". Europe has been able to shape a wide range of important regulations that will continue to shape the global approach to managing the activities of the Big Tech companies.

\section{The African Perspective}

There is a growing adoption of digital platforms in Africa as avenues for social interactions and e-commerce, cutting across different value chains. To a large degree these platforms are tools for a variety of improvements in the production and distribution of old and new products and services in areas that were hitherto traditional and manual. Hence the ability to use these platforms and their tools to create new products and services is an important aspect of innovation. As shown above, the developed world, particularly United States and Europe, are focused on the power of the major platforms over many aspects of our economy and life; but the African continent seem too dependent to have the luxury of these advanced concerns. The platforms of the Big Tech companies are becoming pedestals for delivering new digital products and services that can oil commerce and seamless interactions in Africa.

In spite of these immense benefits of the platforms of the Big Tech companies, we need to ask three key questions. First, are the Big Tech companies under the regulatory oversight of any African country? Secondly, we need to ask whether the Big Tech companies pay taxes to any African country. Lastly, can the African continent withstand the rollercoaster speed and power of the Big Tech companies? In answering these questions, we must admit that Africa is not Europe and certainly not the United States. Hence it will be delusional to equate the situations in the different climes. There is no evidence that any of the Big Tech companies, particularly the big five, is under the regulatory oversight of any country in Africa. Secondly, although Nigeria recently passed a statute that will allow it tax companies like the Big Tech through the Significant Economic Presence (SEP) principle, there is no empirical evidence that any of the Big Tech companies pays taxes to any country in Africa. 
While the last question is too subjective to be answered in this Paper.

There have been specific issues raised on the use and activities on the platforms of the Big Tech companies. A good illustration is the fact that entrepreneurs in Africa have complained about Facebook and Google's high advertising rates, but with Facebook the problem goes deeper ${ }^{1}$. These concerns also revolve around the terms of use of Facebook and WhatsApp, yet the challenge is how can Africa or any country in the continent subordinate these terns to its regulatory review? If Australia is having trouble controlling Facebook, what would we expect from countries in Africa? ${ }^{2}$ Sadly some commentators have made some outrageous suggestions that developing countries should await the outcome of some of the regulatory review of the activities of Big Tech companies in the United States and Europe and see how to tap into the consequent remedies. This infers that developing countries have a lesser sovereignty and must key into efforts of other countries or supranational bodies. In my view this 'demeaning' inference should challenge African countries like Nigeria, Egypt and South Africa, to drive an effort to rein in the Big Tech companies or at least ensure they pay necessary taxes. This will in a long way create the avenue to work individually or coalesce as a continent to develop guidelines or minimum standards for the activities of the Big Tech companies in the continent. In fact at a minimum the Big Tech companies must register or incorporate in the continent, open local offices and ensure they are within the regulatory oversight of national regulators ${ }^{3}$.

Yet we must acknowledge that the African continent is gradually attaining a status as a market for the Big Tech companies, particularly the ones driving the social media platforms. It is also budding as a market for online commerce and easy access to retail products that use to be traded on the streets and markets. This has made a lot of small and medium scale businesses in the African continent to rely on these digital platforms to participate in "value chains," that supports transactions and e-commerce. Clearly in many African countries, participation in global value chains has been seen as an important way to stimulate economic growth, particularly if small and medium size businesses are the beneficiaries of such participation ${ }^{4}$. The extent to which digital platforms have increased such participation by African firms is unclear. A study of value chains in Kenya and Rwanda examined how tourism firms integrated with international tourism sites to provide booking availability and service information, but found that their participation was often limited by a lack of technical skills and by the platforms' managerial requirements ${ }^{5}$. A study of small - scale fresh fruit and vegetable farmers in Tanzania and Kenya focused on the use of certain basic platform technologies (mobile phones, Internet, and Facebook) to access payment systems, get pricing and production information, and reach export markets ${ }^{6}$. Such usage was actually rather small (only 11 percent of farmers surveyed) ${ }^{7}$. Although the use of mobile phones was helpful to small farmers in many local markets, reaching export markets required use of the Internet more than the use of basic mobile phones, a step that excluded farmers who lacked sophistication (technical and linguistic). ${ }^{8}$

\begin{tabular}{|l|l|l|}
\hline Big Tech & Q2 2020 & Q2 2021 \\
\hline Apple & $\$ 11.3 \mathrm{~B}$ & $\$ 21.7 \mathrm{~B}$ \\
\hline Google & $\$ 7.0 \mathrm{~B}$ & $\$ 18.5 \mathrm{~B}$ \\
\hline Microsoft & $\$ 11.2 \mathrm{~B}$ & $\$ 16.5 \mathrm{~B}$ \\
\hline Facebook & $\$ 5.2 \mathrm{~B}$ & $\$ 10.4 \mathrm{~B}$ \\
\hline Amazon & $\$ 5.2 \mathrm{~B}$ & $\$ 7.8 \mathrm{~B}$ \\
\hline
\end{tabular}

Table 2: Net income of some Big Tech companies ${ }^{9}$

The above Table signpost the large incomes generated by the Big Tech companies and the huge possibility for tapping into the revenue stream by both the private and public sectors in Africa. Therefore, to tap into these immense benefits the African continent must also determine the impact of the Big Tech companies on their local economies and the possible disruptive nature of their technologies. This determination will look at the quantum of these incomes that were actually generated in the individual African countries, unless the revenue sources are isolated it will be impracticable to assess and tax them appropriately. This determination must be within the barriers of existing laws and possibly new legislations that will ensure that the platforms will not strangulate local entrepreneurs, dampen innovations or serve as an avenue for incitement and subversion of African governments.

\footnotetext{
${ }^{1}$ Srinivasan, D. (2019). The antitrust case against Facebook: A monopolist's journey towards pervasive surveillance in spite of consumers' preference for privacy. Berkeley Bus. LJ, 16, 39.

${ }^{2} \mathrm{https}: / /$ www.bbc.com/news/technology-56168843

${ }^{3}$ Twitter recently announced that it will be opening an office in Ghana (https://www.africanews.com/2021/04/12/ghana-to-host-twitter-s-firstafrica-office/)

${ }^{4}$ First, H. (2021). Digital Platforms and Competition Policy in Developing Countries. Harry First, Digital platforms and competition policy in developing countries, mai.

${ }^{5}$ Ibid

${ }^{6}$ Ibid

${ }^{7}$ Ibid

${ }^{8}$ Ibid

${ }^{9} \mathrm{https}: / /$ www.statista.com/chart/24775/gafam-net-income/
} 


\section{Is it a Slippery Slope?}

In discussing how slippery the slope is for Africa to regulate and tax the Big Tech companies, it is provident to first review the business models of the companies and the nature of their technologies. First, we must acknowledge that the debate about possible regulation and taxation of the Big Tech companies must centre on the kind of business models they operate and the nature of the technologies they deploy for their platforms. In building any regulatory approach it is key that we understand the exact nature of their business models and even in designing the taxation path, we need to understand Big Tech monetization and the revenue profile of the ecosystem. It is quite evident that to understand the business modelling and the finances of the Big Tech, we also need to dwell on what sustains customer's interests, the breadth of activities of the platforms and the accumulation of data that can be relied on for advertisement by the Big Tech companies. Clearly the business models of both Google and Facebook depend almost entirely on data that customers generate through usage of the platforms. While Apple is less reliant on data directly, it actually partake in the slicing of the data cake of Google, it is estimated that Google paid Apple about \$10billion for being the default search engine on Apple devices ${ }^{1}$.

Secondly, Apple focuses on keeping its customers within its own 'walled garden': an exclusive ecosystem built on its own hardware, covering an expanding scope ${ }^{2}$. Complementors such as app developers help to enhance this experience and pay a significant price (such as a 30\% fee to the App Store) for access, with restrictive terms ${ }^{3}$. Facebook and Google, meanwhile, leverage their users' engagement with various downstream services to generate advertising revenue. Google gathers data from its own services, complementors and Android phones, while Facebook combines data from its online properties (including Instagram and WhatsApp) plus user activity across the web ${ }^{4}$. While much of the advertising revenue is often generated on 'contextual data' (as is the case for Google), collection of data in this vertical provides an incredibly vast but at the same time detailed picture of users' priorities and preferences that allows advertisers to target customers effectively with other advertising products/verticalsand pay Big Tech companies for it (while Big Tech companies are also active in the advertising value chain). Whilst other Big Tech companies like Amazon also sponsor numerous platforms and benefit from extensive customer information; and they are directly related to e-commerce that bridge the digital and physical world. ${ }^{5}$

While we acknowledged that Europe has been active in regulating the Big Tech companies but it is unclear if they have maneuvered round the slippery slope that Africa must navigate to get a proper hold of the Big Tech companies. To get a good view of this matter we need to also review the impact of Big Tech companies within the European continent. The Big Tech companies have a form hold on Europe through its transformation of advertising, where they account for roughly $70 \%$ of digital advertising revenues, with dramatic repercussions for other ecosystem participants. The data-driven nature of the technologies deployed by the Big Tech companies in Europe creates 'winner-take-all' dynamics that emasculates other players in the digital sphere of the continent. This is primarily because the Big Tech companies have created multi-product and diverse service ecosystems that enables them to exploit access to information and data on consumers to strengthen their advantage over other players in the ecosystem in Europe. Although in fairness they have also built multi-participatory ecosystems with other players within Europe that depend on them. With many smaller firms that depend on them. Unfortunately for the other participants the platforms of the Big Tech companies are increasingly the only possible way to access the digital market they dominate. The European Platform-to-Business (P2B) Regulation of $2020^{6}$ is intended to set fairer rules for all players, but its success remains to be seen. Is the Regulation a 'round the curve' measure for Europe?

To really understand how Africa can attain a standard or process that will allow it actually regulate the Big Tech companies, we may need to further interrogate the European attempt further. European regulatory illustrations will revolve around the two key instruments; the Digital Services Act and the Digital Markets Act. The proposed regulations are aimed at curbing unfair practices, encouraging competition and improving Europe's position. But what impact will they actually have on Big Tech? First, it is obvious that stricter privacy regulation will make it much harder for Facebook to deliver targeted advertising by gathering user data from across the web. This may lead Facebook to minimize its reliance on its wide Audience Network, which accounts for $20 \%$ of its total advertisement revenues ${ }^{7}$. Secondly, Google also makes most of its money from advertisements and it is hooked to its capacity to aggregate ultra-fine-grained data from users of its widely used free services ${ }^{8}$. This also allows Google to deliver a best-in-class contextual or hyper-targeted advertising product to varied stakeholders

https://africa.businessinsider.com/tech-insider/google-worked-as-1-company-with-apple-paying-the-iphone-maker-up-to-dollar12billion/2t63mh4

${ }^{2}$ Schrepel, T. (2021). Platforms or Aggregators: Implications for Digital Antitrust Law. Oxford Journal of European Competition Law \& Practice.

${ }^{3}$ Ibid

${ }^{4}$ Ibid

${ }^{5}$ Ibid

${ }^{6} \mathrm{https}: / /$ www.dentons.com/en/insights/alerts/2020/november/6/the-p2b-regulation-new-eu-rules-for-platform-providers

${ }^{7} \mathrm{https} / / /$ www.brookings.edu/blog/techtank/2021/01/06/four-lessons-for-u-s-legislators-from-the-eu-digital-services-act/

${ }^{8} \mathrm{https} / / /$ euagenda.eu/publications/the-european-proposal-for-a-digital-markets-act-a-first-assessment 
and business partners.

The main objective of every regulatory endeavour is to ensure there is a process of oversight, compliance monitoring and effective enforcement. More so when creating such regulatory structure or mechanisms it is also important to aim at creating 'level playing field' for the ecosystem and ensure competition is fair. Therefore, any plan by any African country to regulate the Big Tech companies must focus on the different dynamics of the technologies they deploy and ensure that the areas of regulation is within three key capacities; the capacity to have an oversight over the technologies and the Big Tech companies operating them; secondly, a capacity to monitor and ensure compliance with the regulations and lastly the capacity to enforce the prescriptions and tackle defaulters effectively. Where these capacities are non-existent or inadequate the regulator will be impotent and toothless. Another key slope is the fact that a regulatory endeavour must take into consideration other factors or such regulations might backfire. For instance, excessive privacy regulations that restrict data sharing might actually end up reinforcing 'walled garden' ecosystems, by making them even more closed off' ${ }^{1}$. Therefore, regulators need to stay focused on business models, monetization, data and their implications for competition and rights of citizens. Another key slope is the fact that 'parents' of the Big Tech companies can retaliate against countries that push too hard to regulate and tax them. Hence it is important when navigating the slippery slopes, for the African continent to combine legal imperatives, commercial consideration with international political nuances.

\section{Accelerating forward}

In the light of the several arguments propounded in this paper, particularly as it relates to the slippery slopes that will impact on any African move to regulate and tax the Big Tech companies; the hanging question is on how do we move forward? First, Bradford ${ }^{2}$ is of the view that Big Tech companies, including those in the digital sector, voluntarily extend EU rules to govern their worldwide operations. Thus, it will be erroneous to conclude that the companies are completely uncomfortable or against the European regulatory drive. The voluntary extension of the European standards to other jurisdictions by the Big Tech companies might be purely for economic and technical reasons: given that it is unthinkable to forgo the enormous European market and adjust their products or services to their standards (which often represent the most stringent standards globally). They might find the localisation of their products and services in every region to be expensive and technically complicated by merely creating different "regional" versions of their products and services ${ }^{3}$. Big Tech companies "have an incentive to standardize their production globally and adhere to a single rule as opposed to customizing their production to each individual market"4.

The second issue is on the taxation of the Big Tech companies and we will still circle around the European approach as the way forward. There has been attempt to tax them through digital services taxes with different consequences. France took a lead in taxing the Big Tech companies and stridently argued that they have been deprived of billions in tax receipts each year as the Big Tech companies move their profits away from where business is conducted to where they are taxed the least. While this taxation issue is currently being discussed at the Organisation for Economic Cooperation and Development (OECD) level, the EU Commission has proposed the adoption of a region-wide set of digital tax rules, with the hope that these digital taxes will become global through imitation by non-EU States and as a result of being influenced by the OECD process ${ }^{5}$. However, there is no unity in Europe on this issue as Ireland and some Nordic countries (Sweden, Denmark, and Finland) opposed an EU-wide tax project ${ }^{6}$. They argued that such a tax would have put their export-led economies at a disadvantage and that the appropriate forum to discuss these issues is the OECD. As a result, some countries like France decided to go ahead with their own national versions of a digital tax - with the United States quite unhappy about that ${ }^{7}$. The lack of unity in Europe on the digital taxation issue shows the difficulties of decision-making with regard to critical digital issues at the EU. In some cases, where unanimity rules prevail, "it takes 27 to tango" 8 . But even in other fields, where qualified majority rules prevail it is hard to imagine a "Brussels effect" if internally the project is opposed by an important number of countries 9 .

The last question on the way forward is to ask: how can Africa regulate and tax the Big Tech companies? In considering possible regulatory approaches, the continent must divide the issues into different areas and situate the regulatory approach in a segmented manner. The first regulatory segment is to determine the proper competition and anti-trust prescriptions to review the impact and activities of the Big Tech companies in the digital ecosystem in Africa. The second segment is to review and come up with a well thought telecommunications /

\footnotetext{
${ }^{1}$ Trautman, L. J. (2019). Governance of the Facebook Privacy Crisis. Pitt. J. Tech. L. \& Pol'y, $20,43$.

${ }^{2}$ Bradford, A. (2020). The Brussels effect: How the European Union rules the world. Oxford University Press, USA.

Ibid

${ }^{4}$ Ibid

5https://www.oecd.org/tax/oecd-leading-multilateral-efforts-to-address-tax-challenges-from-digitalisation-of-the-economy.htm

${ }^{6} \mathrm{Ibid}$

${ }^{7}$ https://www.cnbc.com/2020/06/18/us-pulls-out-of-talks-to-tax-tech-giants-in-a-blow-to-europes-plans.html

${ }^{8}$ Bradford, A. (2020). The Brussels effect: How the European Union rules the world. Oxford University Press, USA.

${ }^{9}$ Ibid
} 
internet regulation that will ensure there is an oversight of the platforms and technologies deployed by the Big Tech companies. Thirdly, there is a need to have a data protection regulation that is comprehensive, cross national and effective. Lastly, the African continent must develop strong and effective consumer protection principles that will extend to safe usage of the internet, the platforms and embedded with a charter of usage rights that will regulate the actions of the Big Tech companies.

The first segment relates to issues of competition and it is important to ensure that the Big Tech companies incorporate or register (in any form or method) and come within the regulatory purview of the national regulators in Africa. This will help in making the Big Tech companies responsible and responsive to the market dynamics of the countries, more importantly it will help balance the digital market. The Big Tech are behemoths that must be tempered to avoid them emasculating 'weaker' players in the digital ecosystem and ensuring the market structure remains sustainable for the countries. Yet this regulatory segment must be applied with adequate discretion, in order not to chase away investments or stifle innovations that can 'globalise' the African economy. Consequently, the African countries must act, unlike Europe, with the humility of a party that understand its cravings and need for Foreign Direct Investments (FDIs). More so the platforms of the Big Tech companies provide the citizens of Africa with a strategic opportunity to innovate, join the global market and rely on digital infrastructure for commerce, healthcare, education, tourism, etc.

The second segment relates to telecommunication and internet regulation that is riding on the International Telecommunication Union (ITU) ${ }^{1}$ sets general principles regarding telecom services and the interconnection and interoperability of telecom facilities. It is an important component of the digital ecosystem because the telecommunications services provide the impetus for the operation of the platforms of the Big Tech companies. The ITU facilitates the adoption of international treaties on telecom regulation such as the International Telecommunication Regulations (ITRs) and develops non-binding recommendations on telecom operations for national implementation by states. Besides the ITU, international organizations such as the United Nations Commission on International Trade Law (UNCITRAL) ${ }^{2}$ and the OECD develop policy recommendations and treaties on internet governance and e-commerce. These instruments will help the African continent to align its continental approaches with the developed world and ensure seamless regulatory connectivity. This segment also provides African countries with the only avenue to curtail, restrict and enforce actions against the Big Tech companies. The Big Tech companies are vulnerable due to their complete reliance on telecommunications services for the operation of their platforms.

The third segment centres on data protection and privacy regulation by the African continent. The key purpose of data regulation is the protection of personally identifiable information from unlawful or unethical use; it will also facilitate the protection of personal data as it imposes restrictions on the collection and processing of personal data by Big Tech companies. Currently most African countries lack this important ingredient of data regulation and rely on legacy legislations to manage a matter that is reliant on transformational digital changes. Sadly, even 'big' African countries like Nigeria lack a properly issued regulatory instrument to manage data and the activities of the Big Tech companies. Therefore, the African continent must look at the possibility of having a strong regional approach that can mimick the GDPR, without its pretentious global applicability.

Lastly, countries in Africa must have strong consumer protection principles and charters that will regulate the access to the platforms of the Big Tech companies by their citizens and the management of their activities on these platforms. The downside is that such regulatory approach must never curtail or reduce the freedoms and rights of the individual users of these platforms. Therefore, the regulatory approach must be based on the global rights of free speech and freedom to associate; without any exceptions. Then there will no need to police the citizens in a way that will undermine their rights and manage corrosive contents on these platforms.

\section{Conclusion}

In conclusion, as developing countries grow in their regulatory capacity, there will also be more room to increase the use of technology for regulatory and supervisory purposes as well as to build fundamental digital infrastructure. But the most important aspect of the review of the American and European experiences is the fact that there is a need to have a strong regulatory institution (s) to push these segmented regulatory approaches. Likewise, it is also clear that a continental approach will unearth several challenges, the easiest of which may be the historical fault lines in the continents. Hence, a national approach with collaboration with others will most likely be most effective.

Another key issue is the fact that most African countries have regulators for everything and this creates different layers of sovereign measures that are not always aligned. This confusion cannot help the countries in meeting this hydra headed situation. A good illustration of this multiplicity is the fact that most African countries have different agencies regulating communications, broadcasting, data management, competition and technology.

\footnotetext{
${ }^{1}$ The ITU is within the United Nations structure and its system can help harmonize a global approach to internet governance and regulation of the platforms

${ }^{2}$ https://uncitral.un.org/
} 
This will certainly create regulatory uncertainty and transfer backroom rivalry to the open field. This will also affect the segmentation of the regulatory approach as some of the activities have cross cutting impact and will surely require more than the turf of one agency to manage.

Lastly, the SEP principles can help but it is necessary to upgrade tax assessment and tax collection of the national agencies to ensure they have both technological and manpower capacity to meet the complicated digital business stage. Although this Paper has hesitated to pick specific national efforts to manage the Big Tech companies, it is not oblivious of some attempts in the past that included a ludicrous Social Media Tax in an African country. Consequently, the next endeavour must be technology driven and collaborative enough to tap into the bold initiatives in Europe, otherwise Africa will be isolated in this regard and can be ineffectual in regulating and taxing the 'almighty' Big Tech companies.

\section{References}

1. Carstens, A. (2018). Big tech in finance and new challenges for public policy. speech to FT Banking Summit, 2.

2. Lu, S., Xu, X., Wang, H., Zhao, J., \& Wu, Z. (2018, July). Detecting Systemically Important Platforms in P2P Market of China. In 2018 15th International Conference on Service Systems and Service Management (ICSSSM) (pp. 1-7). IEEE.

3. Arner, D. W., Buckley, R. P., Charamba, K., Sergeev, A., \& Zetzsche, D. A. (2021). BigTech and Platform Finance: Governing FinTech 4.0 for Sustainable Development. Available at SSRN.

4. Srinivasan, D. (2019). The antitrust case against Facebook: A monopolist's journey towards pervasive surveillance in spite of consumers' preference for privacy. Berkeley Bus. LJ, 16, 39.

5. Kwet, M. (2019). Digital colonialism: US empire and the new imperialism in the Global South. Race \& Class, 60(4), 3-26.

6. Reding, V. (2015). Digital Sovereignty: Europe at a Crossroads.

7. Bradford, A. (2020). The Brussels effect: How the European Union rules the world. Oxford University Press, USA.

8. Schrepel, T. (2021). Platforms or Aggregators: Implications for Digital Antitrust Law. Oxford Journal of European Competition Law \& Practice.

9. Trautman, L. J. (2019). Governance of the Facebook Privacy Crisis. Pitt. J. Tech. L. \& Pol'y, $20,43$.

10. Hoffmann, J., \& Johannsen, G. O. (2019). EU-Merger Control \& Big Data On Data-specific Theories of Harm and Remedies. EU Competition Law Remedies in Data Economy, Springer, 19-05.

11. Geradin, D., \& Katsifis, D. (2020). "Trust me, I'm fair": analysing Google's latest practices in ad tech from the perspective of EU competition law. European Competition Journal, 16(1), 11-54.

12. Fenwick, M., Kaal, W. A., \& Vermeulen, E. P. (2019). The'Unmediated'and'Tech-Driven'Corporate Governance of Today's Winning Companies. NYUJL \& Bus., 16, 75.

13. Akman, P. (2021). A Web Of Paradoxes: Empirical Evidence On Online Platform Users And Implications For Competition And Regulation In Digital Markets. Available At Ssrn 3835280.

14. Benzell, S., \& Collis, A. (2020). How to Govern Facebook: A Structural Model for Taxing and Regulating Big Tech. Available at SSRN 3619535.

15. Marco Colino, S. (2021). Towards a Global Big Tech Clampdown?. Agenda Pública, The Chinese University of Hong Kong Faculty of Law Research Paper, (2021-04).

16. Sitaraman, G. (2020). The national security case for breaking up big tech. Knight First Amendment Institute at Columbia, 20-18.

17. First, H., \& Fox, E. M. (2020). Big Tech and Antitrust-Calling Big Tech to Account Under US Law. Available at SSRN 3672750.

18. Lu, S., Xu, X., Wang, H., Zhao, J., \& Wu, Z. (2018, July). Detecting Systemically Important Platforms in P2P Market of China. In 2018 15th International Conference on Service Systems and Service Management (ICSSSM) (pp. 1-7). IEEE.

19. Sitaraman, G. (2021). The Regulation of Foreign Platforms. Available at SSRN 3870781.

20. Baum, I., \& Lachman Messer, D. (2021). Can the Next Amazon or Facebook Be Controlled Before It Becomes Too Powerful. University of Memphis Law Review, Forthcoming.

21. First, H. (2021). Digital Platforms and Competition Policy in Developing Countries. Harry First, Digital platforms and competition policy in developing countries, mai.

22. Fox, E. M. (2019). Platforms, Power, and the Antitrust Challenge: A Modest Proposal to Narrow the USEurope Divide. Neb. L. Rev., 98, 297.

23. Graef, I., \& Costa-Cabral, F. (2020). To regulate or not to regulate Big Tech.

24. Jacobides, M. G. (2020). Regulating Big Tech in Europe: Why, so what, and how understanding their business models and ecosystems can make a difference. Available at SSRN 3765324.

25. Stylianou, K. (2019). Apple v Pepper: the unintended fallout in Europe. Journal of Antitrust Enforcement, 7(3), 457-465. 